\title{
Estimating leaf area index and photosynthetic production in canopies of the mangrove Rhizophora apiculata
}

\author{
B. F. Clough ${ }^{1, *}$, J. E. Ong ${ }^{2}$, W. K. Gong ${ }^{3}$ \\ ${ }^{1}$ Australian Institute of Marine Science, PMB 3, Townsville Queensland 4810, Australia \\ ${ }^{2}$ Centre for Marine and Coastal Studies, Universiti Sains Malaysia, 11800 Penang, Malaysia \\ ${ }^{3}$ School of Biological Sciences, Universiti Sains Malaysia, 11800 Penang, Malaysia
}

\begin{abstract}
Comparative estimates of the leaf area index (LAI) of a mangrove forest canopy in Peninsular Malaysia were obtained by 3 independent methods: (1) from direct measurement of canopy leaf area above a prescribed ground area; (2) from simple measurements of light flux density above and beneath the canopy; (3) from measurements of direct beam transmittance through the canopy. Measurements wore also made of the rate of net photosynthesis at different levels in the canopy. LAIs obtained by direct measurement ranged from 2.2 to 7.4 over 4 replicate $0.25 \mathrm{~m}^{2}$ quadrats, with a mean of 4.9. This high degree of variability was attributed partly to the small quadrat size and partly to the spatial heterogemeity of the canopy. In contrast, estimates of LAI obtained from log averaged measurements of light transmission over a larger area of forest varied by less than $5 \%$ between replicates, with an average of 5.1 Measurements of direct beam transmittance yielded an average canopy LAI of 4.4. Average rates of net photosynthesis ranged from $4 \mu \mathrm{mol} \mathrm{CO} \mathrm{CO}^{-2} \mathrm{~s}^{-1}$ at the bottom of the canopy to about $10 \mu \mathrm{mol} \mathrm{CO}_{2} \mathrm{~m}^{-2} \mathrm{~s}^{-1}$ at the top of the canopy. The LAI weighted average rate of net photosynthesis integrated over the entire canopy was $9 \mu \mathrm{mol} \mathrm{CO}_{2} \mathrm{~m}^{-2}$ leaf $\mathrm{s}^{-1}$. Assuming an eftective daylength of $8 \mathrm{~h}$, total daily net photosynthetic carbon fixation was estimated to be $155 \mathrm{~kg} \mathrm{C} \mathrm{ha-1} \mathrm{d}^{-1}$, giving an

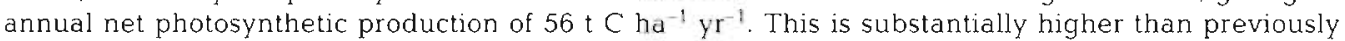
reported for mangrove forests.
\end{abstract}

KEY WORDS: Mangrove $\cdot$ Canopy $\cdot$ Leaf area index Photosynthesis

\section{INTRODUCTION}

Reliable estimates of mangrove forest primary production are essential for many ecological studies, and for assessing management options for these important coastal ecosystems. The most reliable estimates of primary production come from measurement of biomass accumulation over a suitable period of time This usually involves measurement of the increase in $\mathrm{DBH}$ (stem diameter at breast height, ca $1.5 \mathrm{~m}$ ) of all trees in a plot over a period of 1 to 5 yr. DBH measurements are then converted to biomass using allometric relation-

•E-mail: bclough@aims.gov.au ships (Ong et al. 1984, Putz \& Chan 1986, Clough \& Scott 1989). Such measurements are laborious and time consuming, and are generally not well suited to broad scale survey and comparative studies. There is thus a need for simple, survey type methods that can provide comparative data on a broader scale.

A relatively simple survey technique for estimating net photosynthetic production by mangrove forests was described by Bunt et al. (1979). Estimates of net photosynthetic production derived from this technique range from 18 to $34 \mathrm{~kg} \mathrm{C} \mathrm{ha}{ }^{-1} \mathrm{~d}^{-1}$ (equivalent to 6.6 to $11.3 \mathrm{t} \mathrm{Cha}^{-1} \mathrm{yr}^{-1}$ or 13 to $25 \mathrm{t}$ dry matter ha $\mathrm{C}^{-1} \mathrm{yr}^{-1}$ ) for a wide range of mangrove forests in Papua New Guinea and northern Australia (Bunt et al. 1979, Boto et al. 1984). Even neglecting litterfall, accumulation and 
turnover of below-ground biomass, and respiratory losses from living biomass, it is evident that these estimates are barely sufficient to account for the observed accumulation of above-ground biomass (10 to $18 \mathrm{t} d r y$ matter ha-1 $\mathrm{yr}^{-1}$ ) in well-developed mangrove forests on the west coast of Peninsular Malaysia (Ong et al. 1984, Putz \& Chan 1986).

Many studies have shown a close correlation between net primary production and the amount of light absorbed by the plant canopy, which in turn is closely linked to canopy leaf area index (LAI; Monteith 1965a, b, 1972, Norman 1978, 1980). The LAI [area of leaves ( 1 side only) per unit area of ground] of most herbaceous vegetation can be obtained directly by measurement of the total leaf area within a prescribed ground area. For forest canopies, however, direct measurement of LAI over a sufficiently large and representative area is at best difficult and tedious, at worst impossible, and thus the LAI of forest canopies is usually estimated indirectly.

Welles (1990) has reviewed a number of indirect techniques for estimating the LAI of plant canopies. Many of these are based on the measurement of canopy light transmittance using relatively expensive instruments or sensor arrays (e.g. Pierce \& Running 1988, Chason et al. 1991, Ellsworth \& Reich 1993 Martens et al. 1993, Nel \& Wessman 1993). However, the mangrove swamp environment is not conducive to the long-term durability of electronic instruments and a significant proportion of the world's mangrove forests are found in countries with limited financial resources. Hence the need for a simple, affordable technique for estimating LAI in mangrove canopies.

In this paper we describe a simple method for estimating LAI in mangrove forest canopies, based on the measurement of light transmission using a quantum sensor, and compare the results derived from it with those from (1) direct measurement of canopy leaf area above a known cross-sectional area of ground, and (2) measurements of direct beam transmittance using the method originally described by Lang et al. (1985). These estimates of LAI are combined with measurements of canopy photosynthesis to provide an estimate of net daytime canopy photosynthetic production (gross photosynthesis minus daytime respiration, integrated over the whole canopy).

\section{METHODS}

Study site. The study was carried out in a 22 yr old stand of. Rhizophora apiculata in the Matang Mangrove Forest Reserve $\left(100^{\circ} 35^{\prime} \mathrm{E}, 4^{\circ} 50^{\prime} \mathrm{N}\right)$ on the west coast of Peninsular Malaysia. This region has an annual rainfall of $2500 \mathrm{~mm}$ without a strongly pro-
Table 1. Structural characteristics of the Rhizophora apiculata stand. DBH: stem diameter at breast height

\begin{tabular}{lc|}
\hline Parameter & Value \\
\hline Stems ha-1 & 3000 \\
Mean DBH $(\mathrm{cm})$ & 15 \\
Mean height $(\mathrm{m})$ & 20 \\
Basal area $\left(\mathrm{m}^{2} \mathrm{ha}^{-1}\right)$ & 20 \\
\hline
\end{tabular}

nounced wet season, an annual evaporation of 1300 $\mathrm{mm}$, and a relatively uniform average temperature of $27.2^{\circ} \mathrm{C}$. Some structural characteristics of the stand are given in Table 1.

Stratified quadrat sampling. For the stratified measurements of leaf area through the canopy profile, a steel tower $1.5 \times 2.0 \mathrm{~m}$ in cross section and $22 \mathrm{~m}$ high was built to reach the top of the canopy. Quadrats $0.5 \times 0.5 \mathrm{~m}$ in size were attached to the top of the tower on the outside at each of its 4 corners. Weighted strings attached to the corners of the quadrats were used to define a vertical quadrat of $0.5 \times 0.5 \mathrm{~m}$ down through the entire canopy. The canopy area circumscribed by each of the 4 quadrats was divided into vertical layers of between 0.25 and $0.5 \mathrm{~m}$ depth. The area of all leaves (1 side only) in each layer was measured with a Li-Cor LI-3000A electronic planimeter (Li-Cor, Lincoln, NE, USA), Leaf inclination angles were measured with a clinometer (Suunto Instruments, Helsinki, Finland).

Direct beam transmittance (DEMON). Measurements of direct beam transmittance were made with a DEMON LAI instrument (Assembled Electrics, Yagoona, NSW, Australia), originally described by Lang et al. (1985). This instrument uses the transmittance of the direct solar beam to measure gap frequency. The theoretical basis and computational procedures for estimating LAI from direct beam transmittance have been elaborated by Lang and coworkers (Lang et al. 1985, Lang 1986, 1987, Lang \& Xiang 1986). Physically, the instrument consists of a light sensor with a narrow aperture, which is connected to a data logger programmed to derive the information needed to compute both LAI and leaf angle. In operation, readings of direct beam light transmittance beneath the canopy were taken on random walks through the forest over a distance of 10 to $30 \mathrm{~m}$, depending on accessibility, with the light sensor pointed directly at the sun. Sets of readings beneath the canopy were taken at zenith angles ranging from $26^{\circ}$ to $71^{\circ}$. Readings taken beneath the canopy were referenced to readings taken outside the canopy at the beginning and end of each run. The iterative graphical technique for inverting gap fraction data described by Lang \& Xiang (1986) was used to calculate both LAI and the average leaf 
angle, using the whole data set for zenith angles between $26^{\circ}$ and $71^{\circ}$.

Simple light attenuation. Light transmission through the canopy was measured with a Li-Cor LI-190SB quantum sensor on a clear, sunny day between late morning and early afternoon. Measurements were made in the same area in which direct beam transmittance was measured. Four sets of 100 measurements were taken at random over a ground area of about $30 \times$ $30 \mathrm{~m}$ with the quantum sensor held vertically. The photon flux density outside the canopy was measured before and after each set. LAI was calculated from the ratio of the light flux density beneath the canopy $\left(I_{b}\right)$ to the mean light flux density above the canopy $\left(I_{0}\right)$ using the Beer-Lambert Law

$$
I_{\mathrm{b}} / I_{0}=\exp ^{-k L}
$$

which can be re-arranged to give

$$
L=\ln \left(I_{\mathrm{b}} / I_{\mathrm{o}}\right) /-k
$$

where $L$ is the apparent LAI, and $k$ is an extinction coefficient that accounts for the angle and orientation of the foliage.

Values for $L$ calculated according to Eq. (2) assume that the sun is vertically overhead (zenith angle $=0^{\circ}$ ). When this is not the case (zenith angle $>0^{\circ}$ ), L should be corrected to account for the longer pathlength through foliage, such that

$$
L=\left[\ln \left(I_{\mathrm{b}} / I_{\mathrm{o}}\right) /-\mathrm{k}\right] \cdot \cos (\alpha \cdot \pi / 180)
$$

where $\alpha$ is the zenith angle of the sun in degrees and $\pi$ is the constant pi. In this study, $\alpha$ was calculated from latitude, longitude and time of day using a computer program (Turton 1991).

Following Lang \& Xiang (1986) and Nel \& Wessman (1993), logarithms were taken of individual values of $I_{\mathrm{b}} / I_{0}$, and the average of these logged values substituted into Eq. (3). A value for $k$ of 0.56 was used in Eq. (3); this was the mean of that obtained by direct measurement of leaf angles and that obtained from measurements of direct beam transmittance with the DEMON instrument.

Photosynthetic measurements. Measurements of net photosynthesis were made with a Li-Cor LI-6200 portable photosynthesis system, fitted with a custommade leaf chamber (Clough \& Sim 1989). Repeated measurements were made on tagged leaves at various levels from the top to the bottom of the canopy throughout the day, over a period of several days. Rates of photosynthesis were integrated with respect to canopy position and time to yield an average rate of net photosynthesis for the entire canopy during daylight hours.

Calculation of net canopy photosynthetic production. Net daytime photosynthetic production was cal- culated from LAI and the average rate of photosynthesis as

$$
P_{\mathrm{n}}=0.0432 \cdot d \cdot L \cdot A_{\mathrm{c}}
$$

where $P_{\mathrm{n}}$ is daytime net carbon fixation $\left(\mathrm{g} \mathrm{C} \mathrm{m}^{-2}\right.$ ground area $\mathrm{d}^{-1}$ ), $d$ is daylength (h), $L$ is LAI, $A_{c}$ is the average rate of net photosynthesis for the whole canopy (umol $\mathrm{CO}_{2} \mathrm{~m}^{-2}$ leaf $\mathrm{s}^{-1}$ ) and the numerical coefficient, 0.0432, converts $A_{c}$ from units of $\mu \mathrm{mol}$ $\mathrm{CO}_{2} \mathrm{~m}^{-2}$ leaf $\mathrm{s}^{-1}$ to units of $\mathrm{g} \mathrm{C} \mathrm{m}^{-2}$ leaf $\mathrm{h}^{-1}$ It must be emphasised that the estimate of net daytime canopy photosynthetic production derived from Eq. (4) is not an estimate of net primary production. It is simply a measure of the amount of carbon fixed by net photosynthesis in the canopy (gross photosynthesis minus respiration) during daylight hours.

For comparison, estimates of net canopy photosynthetic production were also calculated by the method described by Bunt et al. (1979) and Boto et al. (1984), using the same values for light transmission as those used in Eq. (4). Following Bunt et al. (1979), values of $I_{\mathrm{b}}$ were arranged in ascending order and all values greater than 3 times the mean were excluded. A new mean was then calculated and all values greater than 3 times the mean again excluded. This procedure was repeated until all remaining values of $I_{\mathrm{b}}$ were $\leq 3$ times the mean; values greater than 3 times the mean were assumed to be light gaps (Bunt et al. 1979). Total canopy chlorophyll $\left(\mathrm{mg} \mathrm{m}^{-2}\right)$ was then calculated from the logarithm of the mean $I_{0} / I_{\mathrm{b}}$ using the coefficients given by Bunt et al. (1979) and Boto et al. (1984). Canopy net photosynthetic production was calculated by multiplying total canopy chlorophyll by an assimilation coefficient of $0.57 \mathrm{~g} \mathrm{C} \mathrm{g}^{-1}$ chlorophyll (Bunt et al. 1979, Boto et al. 1984), using an effective production daylength of $8 \mathrm{~h}$ rather than the $12 \mathrm{~h}$ daylength used by Bunt et al. (1979) and Boto et al. (1984). Analysis of changes in photosynthetic rate over the course of a day indicated that net canopy photosynthesis was positive only from about 09:00 $\mathrm{h}$ in the morning to $17: 00 \mathrm{~h}$ in the afternoon.

\section{RESULTS}

\section{Canopy leaf area index}

The fractional vertical distribution of leaf area with depth in each of the four $0.25 \mathrm{~m}^{2}$ quadrats is shown in Fig. 1. Measured LAIs ranged from 2.2 to 7.4 (Fig. 1), with a mean LAI for all 4 quadrats of 4.9. LAI estimates obtained from measurements of canopy light transmission using the quantum sensor over an area of $3600 \mathrm{~m}^{2}$ of the surrounding forest ranged from 4.9 to 5.4 , with an overall average of 5.1 (Table 2). This was not signif- 


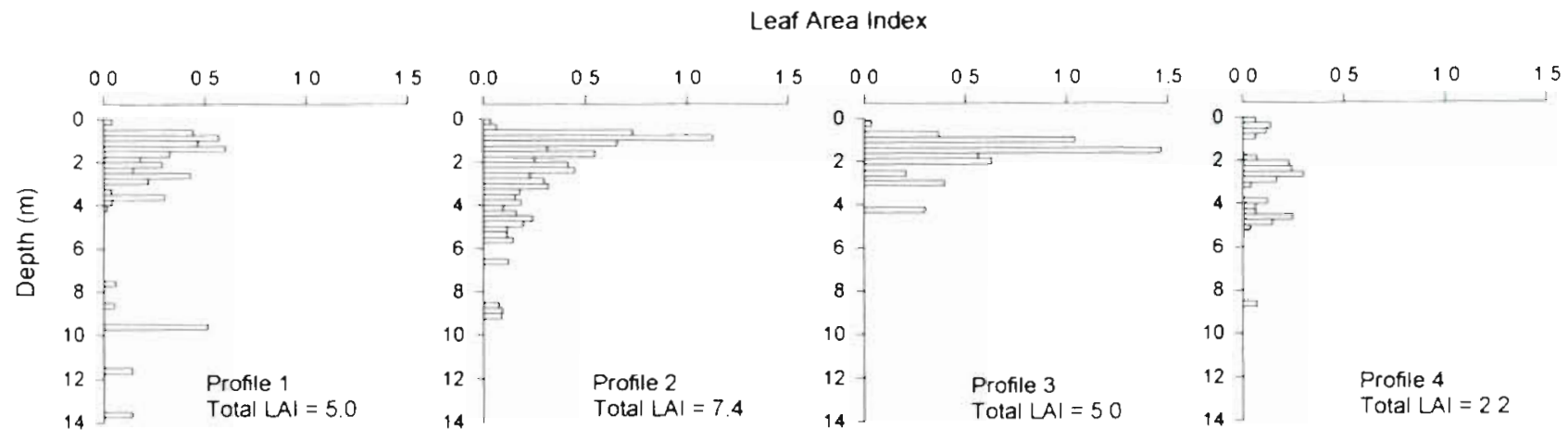

Fig. 1. Rhizophora apiculata. Leaf area profiles for a 22 yr old canopy. Each profile is based on a $0.25 \times 0.25 \mathrm{~m}$ quadrat taken down through the canopy at the 4 corners of a $22 \mathrm{~m}$ high tower

Table 2. Rhizophora apiculata. Leaf area indices (LAI) estimated from light transmission measured by a quantum sensor, and estimates of net canopy photosynthetic production $\left(P_{\mathrm{n}}\right)$ derived from the method described in this study and from that of Bunt et al. (1979). Each set of measurements was made in a different, but adjacent area of the forest. Values in parentheses are standard deviations

\begin{tabular}{|c|c|c|c|}
\hline \multirow{2}{*}{$\begin{array}{c}\text { Measurement } \\
\text { set }\end{array}$} & \multirow[t]{2}{*}{ LAI } & \multicolumn{2}{|c|}{$P_{\mathrm{n}}\left(\mathrm{kg} C \mathrm{ha}^{-1} \mathrm{~d}^{-1}\right)$} \\
\hline & & This study & $\begin{array}{c}\text { Bunt et al } \\
\text { (1979) }\end{array}$ \\
\hline 1 & 4.9 & 135 & 11.0 \\
\hline 2 & 5.0 & 161 & 13.0 \\
\hline 3 & 5.4 & 165 & 13.7 \\
\hline 4 & 5.0 & 157 & 14.3 \\
\hline Mean: & $5.1(0.2)$ & $155(13)$ & $13.0(1.4)$ \\
\hline
\end{tabular}

icantly different from the mean LAI obtained by direct measurement. The LAI estimate of 4.4 obtained from measurements of direct beam transmittance was somewhat lower than those obtained by the other 2 techniques, but whether or not it was significantly different statistically could not be assessed owing to the manner in which the data were processed.

\section{Leaf angle}

Direct measurements of leaf angle were made only in Profile 2 (Fig. 1). Leaf angle (relative to the horizontal plane) decreased more or less linearly from the top to the bottom of the canopy (Fig. 2). The mean leaf angle from the horizontal of all leaves in the profile was $51^{\circ}$ Assuming the leaves to be randomly oriented with respect to azimuth (points of the compass) and uniformly distributed spatially, the canopy light extinction coefficient, $k_{1}$ can be approximated by summing values of $\cos (\theta)$ for all leaves in the profile, where $\theta$ is leaf angle. The calculated canopy light extinction coefficient, $k$, was 0.57 . These values agree well with those obtained from the direct beam transmittance technique, which gave a mean leaf angle of $57^{\circ}$ and a canopy light extinction coefficient, $k$, of 0.54 .

\section{Potential canopy primary production}

Individual instantaneous rates of net photosynthesis ranged from zero up to $20 \mu \mathrm{mol} \mathrm{CO}_{2} \mathrm{~m}^{-2}$ leaf $\mathrm{s}^{-1}$, depending on the time of day and the position of the leaf in the canopy. The average rate of net photosynthesis decreased almost linearly from $10.9 \mu \mathrm{mol} \mathrm{CO}_{2}$ $\mathrm{m}^{-2}$ leaf s $\mathrm{s}^{-1}$ at the top of the canopy to $4.9 \mu \mathrm{mol} \mathrm{CO}_{2} \mathrm{~m}^{-2}$ leaf $\mathrm{s}^{-1}$ at the bottom (Fig. 3). These rates were combined with an average profile of leaf area index to cal-

\section{Average Leaf Angle (degrees)}

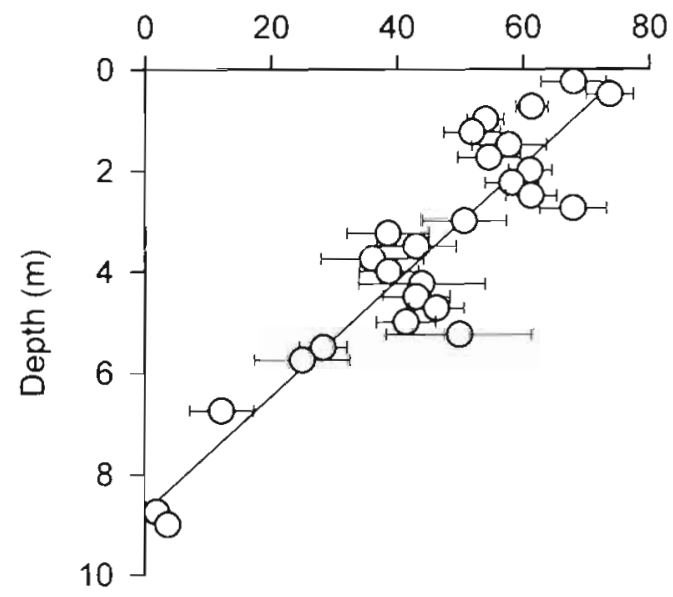

Fig. 2. Rhizophora apiculata. Change in mean leaf angle with canopy depth for Profile 2 (see Fig. 1). Each point is the mean angle for a canopy layer of $0.25 \mathrm{~m}$ in thickness. Error bars are standard deviations 


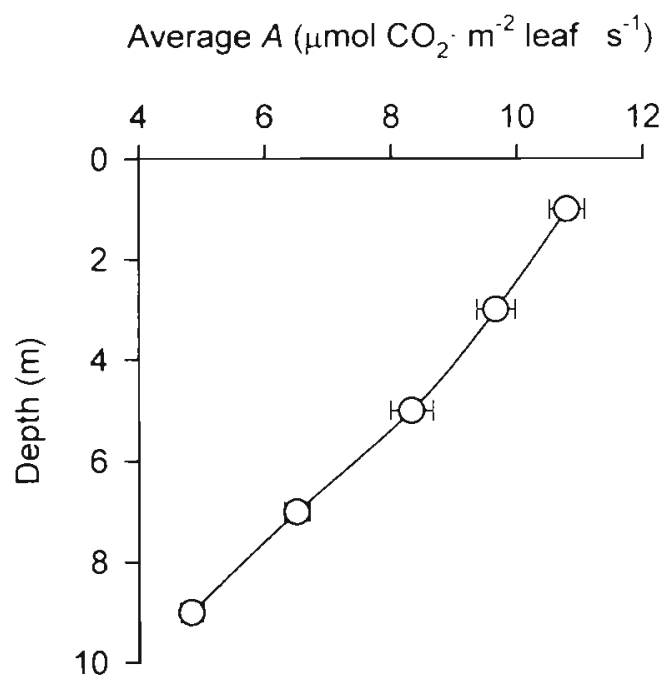

Fig. 3. Rhizophora apiculata. Change in the average rate of net photosynthesis $(A)$ with depth in the canopy. Error bars are standard deviations

culate an LAI-weighted average photosynthetic rate $\left(A_{c}\right)$ over the whole canopy; the calculated value for $A_{c}$ was $9.05 \mu \mathrm{mol} \mathrm{CO}_{2} \mathrm{~m}^{-2}$ leaf $\mathrm{s}^{-1}$. This relatively high value for $A_{c}$ results from the large fraction of total LAI that occurs in the uppermost $2 \mathrm{~m}$ of the canopy, which typically accounted for more than $50 \%$ of the total canopy LAI, and the relatively small number of leaves at depths greater than $5 \mathrm{~m}$, where rates of net photosynthesis were low (Figs. $1 \& 3$ ). A value of $9 \mu \mathrm{mol} \mathrm{CO}_{2}$ $\mathrm{m}^{-2}$ leaf $\mathrm{s}^{-1}$ was used for $A_{c}$ in Eq. (4) when calculating net canopy photosynthetic production.

Estimates of net daytime canopy photosynthetic production using Eq. (4) ranged from 135 to $165 \mathrm{~kg} \mathrm{C} \mathrm{ha}^{-1}$ $\mathrm{d}^{-1}$, with a mean of $155 \mathrm{~kg} \mathrm{C} \mathrm{ha}^{-1} \mathrm{~d}^{-1}$ (Table 2). As shown in Table 2 , this is more than an order of magnitude greater than that calculated using the method of Bunt et al. (1979). A mean net daytime canopy photo- synthetic production of $155 \mathrm{~kg} \mathrm{C} \mathrm{ha} \mathrm{C}^{-1}$ is equivalent to $56 \mathrm{t} \mathrm{C} \mathrm{ha}^{-1} \mathrm{y}^{-1}$ or approximately $110 \mathrm{t}$ dry matter ha ${ }^{-1} \mathrm{yr}^{-1}$

A preliminary carbon balance for $22 \mathrm{yr}$ old Rhizophora apiculata trees in the Matang Forest Reserve is shown in Table 3, using the present estimate of net daytime canopy photosynthesis and previously published data for biomass, mean annual increment of above-ground biomass, litterfall (Ong et al. 1984), and below-ground root biomass (Gong \& Ong 1990). Of the total annual net daytime photosynthetic production of $56 \mathrm{t} \mathrm{C} \mathrm{ha-1} \mathrm{yr}^{-1}, 22 \%$ is respired by the foliage overnight and $8 \%$ is lost as litter, while about 11 and $1 \%$ are accumulated as above-ground and belowground biomass, respectively. This leaves about 58\%, or $31 \mathrm{t} \mathrm{C} \mathrm{ha}^{-1} \mathrm{yr}^{-1}$ for root turnover and respiration by the woody above-ground components and belowground roots.

\section{DISCUSSION}

\section{Leaf area index}

The DEMON instrument has been shown previously to provide reliable indirect estimates of LAI and average leaf angle in both crop and terrestrial forest canopies (Lang et al. 1985, 1991, Lang 1986, 1987, Lang \& Xiang 1986, Lang \& McMurtrie 1992, Sommer $\&$ Lang 1994). In our study, there was good agreement between the average leaf angle obtained by direct measurement $\left(51^{\circ}\right)$ and that obtained by the DEMON instrument $\left(57^{\circ}\right)$, corresponding estimates of the canopy light extinction coefficient, $k$, being 0.57 (direct measurement) and 0.54 (DEMON). The mean leaf angle of $54^{\circ}$ and mean canopy light extinction coefficent of 0.56 obtained from the DEMON instrument and direct measurement is very similar to average leaf

Table 3. Rhizophora apiculata. Preliminary carbon balance for 22 yr old trees in the Matang Forest Reserve

\begin{tabular}{|c|c|c|c|}
\hline Component & $\mathrm{gC} \mathrm{m}^{-2} \mathrm{~d}^{-1}$ & $\mathrm{t} C h \mathrm{a}^{-1} \mathrm{yr}^{-1}$ & t dry matter ha ${ }^{-1} \mathrm{yr}^{-1}$ \\
\hline Net daytime canopy photosynthetic production & 15.6 & 56 & 110 \\
\hline \multicolumn{4}{|l|}{ Carbon allocation } \\
\hline Above-ground biomass accumulation & 1.8 & 6.5 & 13.0 \\
\hline Below-ground biomass accumulation ${ }^{a}$ & 0.2 & 0.6 & 1.2 \\
\hline Litter fall & 1.2 & 4.4 & 8.8 \\
\hline Below-ground root turnover & $?$ & $?$ & $?$ \\
\hline Nighttime foliar respiration ${ }^{\mathrm{b}}$ & 3.5 & 13 & 25 \\
\hline Below-ground root respiration ${ }^{c}$ & $?$ & $?$ & $?$ \\
\hline Above-ground stem, branch and root respiration ${ }^{c}$ & $?$ & ? & ? \\
\hline \multicolumn{4}{|c|}{$\begin{array}{l}\text { a Assumes that below-ground root biomass accumulates at a rate of } 8.5 \% \text { of the total biomass (Gong \& Ong 1990) } \\
{ }^{b} \text { Assumes a respiration rate of } 1 \mu \mathrm{mol} \mathrm{CO}_{2} \mathrm{~m}^{-2} \text { leaf area } \mathrm{s}^{-1} \text { (authors' unpubl. data) } \\
\text { "No data presently available for these components }\end{array}$} \\
\hline
\end{tabular}


angles and canopy light extinction coefficients for other Rhizophora spp. forests of varying age in Malaysia, Thailand and northeastern Australia (authors' unpubl. data). It appears that a value of 0.55 for $k$ can be used with confidence for estimating LAI of Rhizophora spp. canopies from simple measurements of light flux density above and beneath the canopy, using Eq. (3).

The other indirect method used in this study, employing a quantum sensor to measure light transmission, is similar in principle to the appraach used by Pierce \& Running (1988), Chason et al. (1991), Nel \& Wessman (1993), and Ellsworth \& Reich (1993). Unlike many of these studies, we did not correct for diffuse radiation, which in theory should result in understimation of LAI. However, this technique yielded an estimate of LAI that was similar to that obtained by direct measurement and some 16\% higher than that obtained using the DEMON instrument.

Two important assumptions were made in the analysis of the direct beam transmittance and canopy light attenuation methods used in this study. Firstly, it was assumed that canopy elements were randomly dispersed spatially. In our study this assumption was not strictly valid, because the leaves of Rhizophora species are clumped together in rosettes, which themselves are usually aggregated at the ends of small branches. Furthermore, Rhizophora species appear to be canopy shy; the canopies of individual trees tend to be discrete elements, with small gaps between the crowns of adjacent trees. In theory, such aggregation of both the foliage elements and the crowns of individual trees would be expected to increase the number of light gaps, thereby allowing more light through the canopy and leading to an underestimate of LAI. In practice, however, this may not lead to a significant underestimate of LAI (Norman et al, 1971. Norman \& Jarvis 1975, Norman 1978).

The second assumption that leaves are the only canopy elements that intercept light was also violated by the methods employed in our study, as in most studies of forest canopies, where interception of light by non-photosynthetic organs such as branches and stems leads to overestimation of LAI. The error in ignoring the contribution of branches and stems is difficult to quantify. However, it is likely to be relatively small when the sun is directly overhead (zenith angle $=0^{\circ}$ ) because stems are not then in the path of the solar beam. We would expect the error attributable to stems to increase with increasing zenith angle, when the sun is closer to the horizon and stems occupy an increasingly larger fraction of the view of the light sensor.

We cannot explain the discrepancy between the LAI obtained by the DEMON instrument and that obtained from the quantum sensor technique. Clumping or aggregation of foliage elements and the inclusion of diffuse radiation might both be expected to lead to underestimation of LAI using the quantum sensor technique, but our results suggest otherwise.

Reliable estimation of LAI from measurement of light transmission by a quantum sensor requires that the radiation flux density above the canopy does not change over the period during which measurements beneath the canopy are made. In practice this means that measurements should be made on cloud-free days or, at the very least, while the sun is unobstructed by cloud during measurements. Furthermore, it is desirable that measurements be made when the sun is more or less directly overhead to minimise errors due to penumbral effects and diffuse radiation.

The 4 leaf area profiles shown in Fig 1 illustrate the spatial heterogeneity of the foliage of many closedcanopy mangrove stands. The quantum sensor technique used in this study appears to provide a reliable. spatially averaged estimate of the LAI of mangrove stands, is simple to use, and can be easily applied over a range of stand densities, provided that the precautions described above are followed

\section{Net canopy photosynthetic production}

The method used in this study to estimate net canopy photosynthetic production requires 3 parameters: LAI an average rate of canopy photosynthesis, and daylength. While it is relatively easy to obtain an estimate of LAI using the method described in this paper, it is more difficult to obtain a reliable estimate of average canopy photosynthetic rate. The approach taken in this study was to integrate measurements of the instantaneous rates of net photosynthesis of leaves at different levels in the canopy from top to bottom throughout the day. The highest instantaneous rate of net photosynthesis of about $25 \mu \mathrm{mol} \mathrm{CO}_{2} \mathrm{~m}^{-2}$ leaf $\mathrm{s}^{-1}$, and the overall average rate of photosynthesis of $9 \mu \mathrm{mol} \mathrm{CO} \mathrm{Cm}^{-2}$ leaf $\mathrm{s}^{-1}$ for the whole canopy, are similar to those reported by Gong et al. (1992) for Rhizophora apiculata in the Matang mangrove forest, and by Clough \& Sim (1989) and Cheeseman et al. (1991) for mangrove forests in areas of moderate salinity, moderate to high rainfall and persistent cloud cover in Papua New Guinea and northeastern Australia. Under less favourable conditions, usually associated with edaphic or climatic aridity due to high salinity, low soil-water content or exposure to persistently high solar radiation, rates of net canopy photosynthesis may be substantially lower; in such cases, the average rate of net canopy photosynthesis may be only 4 to $5 \mu \mathrm{mol} \mathrm{CO}_{2}$ $\mathrm{m}^{-2}$ leaf $\mathrm{s}^{-1}$ (Moore et al. 1972, 1973, Clough \& Sim 1989, Smith et al. 1989, Lin \& Sternberg 1992). 
The estimates of net canopy daytime photosynthetic production obtained here were about 1 order of magnitude higher than those derived using the method of Bunt et al. (1979), using essentially the same set of raw data for the same area of forest. Clearly, the estimate derived from the method of Bunt et al. (1979) is not sufficient to sustain measured rates of biomass accumulation and litterfall in mangrove forests of similar age and structure in the Matang area (Ong et al. 1984, Putz \& Chan 1986). As shown in Table 3, our method provides an estimate that is of the right order of magnitude to support the observed rates of above-ground biomass accumulation and litterfall, as well as respiration, and the turnover and accumulation of below-ground roots, rates for which are not presently available. An analysis of several studies indicates that respiration by branches, stems and roots may account for 25 to $50 \%$ of photosynthetically assimilated carbon in temperate terrestrial forest species (Landsberg 1986), and we would not expect mangroves to differ significantly in this respect.

\section{Conclusions}

The results of this study indicate, firstiy, that reliable estimates of leaf area index of a Rhizophora apiculata canopy can be obtained from measurements of photon flux density above and below the canopy using a simple quantum sensor. The technique should work equally well in closed canopies of other mangrove species. In that case, it would be necessary to obtain an independent measure of the canopy light extinction coefficient, $k$.

Secondly, current estimates of net canopy production derived using the former method of Bunt et al. (1979) should be revised upward by about an order of magnitude. Data already obtained using the former method can easily be recalculated using the method described here. Ideally, the recalculation should be based on measurements of photosynthetic activity made in the same area of forest in which the canopy light measurements were made. In the absence of direct measurements of photosynthetic activity, it may still be possible to obtain realistic estimates of net canopy photosynthetic production using published data for photosynthetic rates under similar climatic and edaphic conditions (e.g. Moore et al. 1972, 1973, Clough \& Sim 1989, Smith et al. 1989, Gong et al. 1992. Lin \& Sternberg 1992)

Finally, our results indicate the critical need for reliable measurements of respiration by woody tissues and below-ground roots, as well as root production and turnover. Such studies need to be carried out over a range of environmental and site conditions, because carbon partitioning between above-ground and belowground components of Rhizophora trees appears to be influenced by interactions between soil water/salinity and climatic conditions (Clough et al. 1997).

Acknowledgements. We thank Wong Hwee Kheng, Wong Ya Ping, Mohd. Hussain Yahya, Ab. Rahaman Abdullah, Bakar Othman and Johari Othman for field support and assistance, and Robin Sim for assistance with data processing. Glenn De'Ath provided statistical advice, and Dan Alongi and several anonymous reviewers provided constructive comments on an earlier draft. This work received partial support from the AIDAB funded ASEAN-Australia Marine Science Project: Living Coastal Resources, and from the UNDP/UNESCO Regional Mangroves Project RAS/86/120. We are also grateful to the Universiti Sains Malaysia and the Government of Malaysia (IRPA Project 123/3408/2401) for infrastructural and equipment support. This is contribution no. 886 from the Australian Institute of Marine Science.

\section{LITERATURE CITED}

Boto KG, Bunt JS, Wellington JT (1984) Variations in mangrove forest productivity in Northern Australia and Papua New Guinea. Estuar Coast Shelf Sci 19:321-329

Bunt JS, Boto KG, Boto G (1979) A survey method for estimating potential levels of mangrove forest primary production. Mar Biol 52:123-128

Chason JW, Baldocchi DD, Huston MA (1991) A comparison of direct and indirect methods for estimating forest canopy leaf area. Agric For Meteorol 57:107-28

Cheeseman JM, Clough BF, Carter DR, Lovelock CE, Ong JE, Sim RG (1991) The analysis of photosynthetic performance in leaves under field conditions: a case study using Bruguiera mangroves. Photosynth Res 29:11-22

Clough BF, Scott K (1989) Allometric relationships for estimating above-ground biomass in six mangrove species. For Ecol Manag 27:117-127

Clough BF, Sim RG (1989) Changes in gas exchange characteristics and water use efficiency of mangroves in response to salinity and vapour pressure deficit. Oecologia $79: 38-44$

Clough BF, Dixon P, Dalhaus O (1997) Allometric relationships for estimating biomass in multi-stemmed mangrove trees. Aust J Bot (in press)

Ellsworth DS, Reich PB (1993) Canopy structure and vertical patterns of photosynthesis and related leaf traits in a deciduous forest. Oecologia 96:169-178

Gong WK, Ong JE (1990) Plant biomass and nutrient flux in a managed mangrove forest in Malaysia. Estuar Coast Shelf Sci 31:519-530

Gong WK, Ong JE, Clough BF (1992) Photosynthesis in different aged stands of a Malaysian mangrove ecosystem. In: Chou LM, Wilkinson CR (eds) Third A.SEAN Science and Technology Week Conference Proceedings, Vol 6, Marine science: living coastal resources, 21-23 Sept 1992, Singapore. National University of Singapore and National Science and Technology Board, Singapore, p 345-351

Landsberg JJ (1986) Physiological ecology of forest production. Academic Press, London

Lang ARG (1986) Leaf area and average leaf angle from transmission to direct sunlight. Aust J Bot 34:349-55

Lang ARG (1987) Simplified estimate of leaf area index from transmittance of the sun's beam. Agric For Meteorol 41: $179-186$ 
Lang ARG, McMurtrie RE, Benson ML (1991) Validity of surface area indices of Pinus radiata estimated from transmittance of the sun's beam. Agric For Meteorol 57: $157-1.70$

Lang ARG, McMurtre RE (1992) Total leaf areas of single trees of Eucalyptus grandis estimated from transmittances of the sun's beam. Agric For Meteorol 58:79-92

Lang ARG, Xiang Y (1986) Estimation of leaf area index from transmission of direct sunlight in discontinuous canopies. Agric For Meteorol 37:229-243

Lang ARG, Xiang Y, Norman JM (1985) Crop structure and the penetration of direct sunlight. Agric For Meteorol 35:83-101

Lin G. Sternberg LSL (1992) Comparative study of water uptake and photosynthetic gas exchange between scrub and fringe red mangroves, Rhizophora mangle L. Oecologia 90:399-403

Martens SN, Ustin SL, Rousseau RA (1993) Estimation of tree canopy leaf area index by gap fraction analysis. For Ecol Manag 61:91-108

Monteith JL (1965a) Light distribution and photosynthesis in field crops. Ann Bot 29:19-37

Monteith JL (1965b) Light and crop production. Field Crop Abstr 18:214-219

Monteith JL (1972) Solar radiation and productivity in tropical ecosystems. J Appl Ecol 9:747-766

Moore RT, Miller PC, Albright D. Tieszen LL (1972) Comparative gas exchange characteristics of three mangrove species during the winter. Photosynthetica 6:387-393

Moore RT, Miller PC, Ehleringer J, Lawrence W (1973) Seasonal trends in gas exchange characteristics of three mangrove species. Photosynthetica 7:387-394

Nel EM, Wessman CA (1993) Canopy transmittance models for estimating forest leaf area index. Can J For Res 23: $2579-2586$

Norman JM (1978) Modeling the complete crop canopy. In: Barfield BJ, Gerber JF (eds) Modification of the aerial environment of plants. American Society of Agricultural Engineers, St Joseph, MI, p 249-277

Editorial responsibility: Daniel Alongi (Contributing Editor), Townsville, Australia
Norman JM (1980) Interfacing leaf and canopy light interception models. In: Hesketh JD, Jones JW (eds) Predicting photosynthesis for ecosystem models II. CRC, Boca Raton, p 49-67

Norman JM, Jarvis PG (1975) Photosynthesis in Sitka Spruce (Picea sitchensis (Bong) Carr.) V. Radiation penetration theory and a test case. J Appl Ecol 12:839-878

Norman JM, Miller EE. Tanner CB (1971) Light intensity and sunfleck size distribution in plant canopies. Agron J 63: $743-748$

Ong JE, Gong WK, Wong CH, Dhanarajan G (1984) Contribution of aquatic productivity in managed mangrove ecosystem in Malaysia. In: Soepadmo E, Rao AN, Macintosh DJ (eds) Proceedings Asian Symposium on Mangrove Environment-Research and Management. University of Malaya, Kuala Lumpur, p 209-215

Pierce LL, Running SW (1988) Rapid estimation of coniferous forest leaf area index using a portable integrating radiometer. Ecology 69:1762-1767

Putz FE, Chan HT (1986) Tree growth, dynamics, and productivity in a mature mangrove forest in Malaysia. For Ecol Manage 17:211-230

Smith JAC, Popp M, Luttge U, Cram WJ, Diaz M, Griffiths $H_{\text {, }}$ Lee HSJ, Medina E, Schafer C, Stimmel KH, Thonke B (1989) Ecophysiology of xerophytic and halophytic vegetation of a coastal alluvial plain in northern Venezuela. VI. Water relations and gas exchange of mangroves. New Phytol 111:293-307

Sommer KJ، Lang ARG (1994) Comparative analysis of two indirect methods of measuring leaf area index as applied to minimal and spur pruned grape vines. Aust J Plant Physiol 21:197-206

Turton SM (1991) Solar radiation regimes in rainforest understoreys, gaps and clearings, with special reference to Northeast Queensland. PhD thesis, James Cook University, Townsville

Welles JM (1990) Some indirect methods of estimating canopy structure. Remote Sens Rev 5:31-43

Submitted: January 20, 1997; Accepted: August 15, 1997

Proofs received from author(s): November 17, 1997 